\title{
Superoxide dismutases and glutaredoxins have a distinct role in the response of Candida albicans to oxidative stress generated by the chemical compounds menadione and diamide
}

\author{
Guilherme Maranhão Chaves/ ${ }^{+}$, Walicyranison Plinio da Silva \\ Laboratório de Micologia Médica e Molecular, Departamento de Análises Clínicas e Toxicológicas, \\ Centro de Ciências da Saúde, Universidade Federal do Rio Grande do Norte, Natal, RN, Brasil
}

To cope with oxidative stress, Candida albicans possesses several enzymes involved in a number of biological processes, including superoxide dismutases (Sods) and glutaredoxins (Grxs). The resistance of C. albicans to reactive oxygen species is thought to act as a virulence factor. Genes such as SOD1 and GRX2, which encode for a Sod and Grx, respectively, in $\mathrm{C}$. albicans are widely recognised to be important for pathogenesis. We generated a double mutant, $\Delta \mathrm{grx} 2 / \mathrm{sod} 1$, for both genes. This strain is very defective in hyphae formation and is susceptible to killing by neutrophils. When exposed to two compounds that generate reactive oxygen species, the double null mutant was susceptible to menadione and resistant to diamide. The reintegration of the SOD1 gene in the null mutant led to recovery in resistance to menadione, whereas reintegration of the GRX2 gene made the null mutant sensitive to diamide. Despite having two different roles in the responses to oxidative stress generated by chemical compounds, GRX2 and SOD1 are important for $\mathrm{C}$. albicans pathogenesis because the double mutant $\Delta \mathrm{grx} 2 / \mathrm{sod} 1$ was very susceptible to neutrophil killing and was defective in hyphae formation in addition to having a lower virulence in an animal model of systemic infection.

Key words: Candida albicans - superoxide dismutases - glutaredoxins - phagocytosis - virulence

Candida albicans is a diploid yeast belonging to the human normal microbiota and may occur as a commensal organism of the oral cavity, gastrointestinal tract and vagina of healthy individuals (Colombo et al. 2007, Southern et al. 2008, Chaves et al. 2012). Several factors may trigger its transition from commensalism to infection. As a consequence, this harmless yeast may become pathogenic, predominantly depending on the host's immune status. Immunocompromised hosts, diabetic patients and pregnant women are the populations that are the most susceptible to candidiasis (Colombo et al. 2007).

Despite the fact that the human host plays the major role in the establishment of successful candidiasis, the fungus also possesses attributes of virulence. For C. albicans, its widely advocated virulence traits include the ability to adhere to host epithelial cells, which is the first step in the acquisition and maintenance of a stable yeast population in the oral cavity, the secretion of hydrolytic enzymes (proteinases and phospholipases), the ability to grow with different morphologies (blastoconidia, pseudo hyphae and true hyphae), i.e., because filamentation appears to be related to tissue invasion, biofilm formation and its resistance to the oxidative burst generated inside phagocytic cells (Karkowska-Kuleta et al. 2009, Chaves et al. 2012).

Financial support: CAPES

+ Corresponding author: guilherme.chaves@ufrnet.br

Received 1 May 2012

Accepted 26 October 2012
In addition to combating reactive oxygen species (ROS) from their own metabolism, pathogenic organisms also react against the primary oxidative burst generated by macrophages and polymorphonuclear neutrophils (PMNs), which utilise the nicotinamide adenine dinucleotide phosphate oxidase present in the membrane to produce the superoxide anion $\left(\mathrm{O}_{2}^{-}\right)$(Battistoni et al. 1998, Lamarre et al. 2001)

The role of the innate immune response in C. albicans is related to its recognition by dendritic cells, macrophages and neutrophils. This process is mediated by pattern recognition receptors involved in phagocytosis and the clearance of the pathogen (Gow et al. 2007, Taylor et al. 2007), such as Toll-like receptors and lectin receptors. These receptors recognise the pathogen-associated molecular patterns that are commonly found in a wide range of pathogens, but not in the mammalian host (Nicola et al. 2008). In response to ROS produced by phagocytic cells, C. albicans possesses several enzymes involved in a number of biological processes, such as superoxide dismutases (Sods), catalases (Cats), thioredoxin (Trx) peroxidases (Prxs) and glutaredoxins (Grxs) (Chaves et al. 2007, Tosello et al. 2007).

Several genes involved in the oxidative stress response in $C$. albicans have been recognised as virulence factors. For example, the disruption of the CAT1 gene in this yeast led to an increased sensitivity to hydrogen peroxide $\left(\mathrm{H}_{2} \mathrm{O}_{2}\right)$ and an attenuation of virulence in an animal model (Wysong et al. 1998).

In addition, $C$. albicans possesses six different genes that encode for Sods. These enzymes possess antioxidant properties that catalyse the dismutation of $\mathrm{O}_{2}^{-}$into molecular oxygen and $\mathrm{H}_{2} \mathrm{O}_{2}$, which can then be detoxified by 
Cat (Chaves et al. 2007), thereby scavenging the toxic effects of $\mathrm{O}_{2}$ (Frohner et al. 2009). These Sods include cytoplasmic Sod1 and Sod3, mitochondrial Sod2 and the cell surface GP-anchored Sod4, Sod5 and Sod6 (Martchenko et al. 2004, Frohner et al. 2009, Bink et al. 2011).

The cytosolic $\mathrm{Cu} / \mathrm{Zn}$ SOD encoded by SODI is important for virulence in C. albicans. The C. albicans $\Delta$ sodl mutant has been shown to be attenuated in virulence in an animal model of systemic infection (Hwang et al. 2002, Chaves et al. 2007) and more susceptible to macrophage (Hwang et al. 2002) and PMN killing (Chaves et al. 2007). The mitochondrial Sod 2 of C. albicans has been ruled out as a putative virulence factor, but the $\Delta \operatorname{sod} 2$ mutant is more sensitive to heating, ethanol and high concentrations of salts, indicating no direct role in virulence, but a function in different environmental stresses (Hwang et al. 2003).

SOD5 expression is increased in $C$. albicans yeast cells exposed to PMNs (Fradin et al. 2005) and during morphological change from yeasts to hyphae (Nantel et al. 2002). However, while $\operatorname{sod} 1 \Delta$ is hypersensitive to killing by a macrophage cell line in vitro (Hwang et al. 2002), the same was not observed for sod5 $\Delta$ (Martchenko et al. 2004), indicating that the virulence role of Sod5 may be due to a resistance to different phagocytic cells.

Frohner et al. (2009) recently demonstrated that the Sod 4 and Sod5 produced by innate immune response cells are extremely important as ROS scavengers. When both the SOD4 and SOD5 genes were disrupted in $C$. albicans, the double mutant generated $(\Delta \operatorname{sod} 4 /$ sod 5$)$ was extremely susceptible to in vitro macrophage killing (Frohner et al. 2009).

Grx are cytosolic enzymes that act as thiol oxidoreductases and are responsible for the reduction of protein disulphides or glutathione (GSH)-protein mixed disulphides. This reaction also involves cysteine residues from the enzyme's active site (Herrero et al. 2008). Chaves et al. (2007) demonstrated that a mutant lacking the GRX2 gene, which encodes a Grx in C. albicans, was deficient in hyphae formation and more susceptible to PMN killing. This $\Delta g r x 2$ mutant was also attenuated in virulence in a murine model of systemic infection and susceptible to menadione, but resistant to diamide.

Srinivasa et al. (2012) recently characterised a Prx in C. albicans that reduces both $\mathrm{H}_{2} \mathrm{O}_{2}$ and tert-butyl hydroperoxide (t-BOOH). The deletion of the PRX gene led to a mutant that was virtually insensitive to $\mathrm{H}_{2} \mathrm{O}_{2}$, diamide and menadione, but susceptible to low concentrations of $\mathrm{t}$ $\mathrm{BOOH}$, indicating different roles for genes related to oxidative stress and induced by chemical compounds.

Some genes related to oxidative stress are also regulated during hyphae formation and appear to be somehow related to C. albicans morphogenesis (Hwang et al. 2002, Nantel et al. 2002, Martchenko et al. 2004, Chaves et al. 2007). In addition, Schroter et al. (2000) analysed the amount of ROS produced when cells were incubated in $10 \%$ serum. Those authors found that ROS were produced in large amounts in a strain that formed true hyphae. Recently, it has been demonstrated that hyphal differentiation is induced by a subtoxic concentration of exogenous $\mathrm{H}_{2} \mathrm{O}_{2}$ in C. albicans (Nasution et al. 2008).
Younes et al. (2011) reported that the HWP2 gene, which is involved in morphogenesis, adherence and biofilm formation in C. albicans, is also required to tolerate oxidative stress because the mutant $\Delta h w p 2$ is susceptible to $\mathrm{H}_{2} \mathrm{O}_{2}$ compared with the wild-type strain.

As mentioned, previous studies have demonstrated that the SOD1 gene and GRX2 gene play a role in the virulence of $C$. albicans (Hwang et al. 2002, Chaves et al. 2007). When separately disrupted, these genes led to an attenuation of virulence in an animal model of systemic infection. Furthermore, the disruption of these genes, particularly the GRX2 gene, appears to influence morphogenetic development. Other phenotypic changes were found between the single mutants $\Delta$ sodl and $\Delta g r x 2$, such as different responses to oxidative stress induced by menadione and diamide induction. We hypothesised that the disruption of two of the oxidative stress genes would alter virulence and/or interfere with other $C$. albicans phenotypic properties. Therefore, we generated the double mutant $\Delta$ sodl/grx 2 and re-integrated each of these genes separately, creating the $\Delta$ sodl/grx $2+G R X 2$ and $\triangle$ sodl/gr $x 2+S O D 1$ reintegrant strains.

\section{MATERIALS AND METHODS}

Strains, media and culture conditions - All C. albicans strains used and constructed in this study are listed in Table I. These strains were stored at $-80^{\circ} \mathrm{C}$ in $20 \%$ (v:v) glycerol and later subcultured on Sabouraud agar. The following media were routinely used to grow the fungi: nutrient broth + glucose + YE (NGY) broth: $1 \mathrm{~g} / \mathrm{L}$ neopeptone (Difco, Detroit, MI, USA), $4 \mathrm{~g} / \mathrm{L}$ glucose and $1 \mathrm{~g} / \mathrm{L}$ yeast extract; yeast extract-peptone-dextrose (YPD) broth: $10 \mathrm{~g} / \mathrm{L}$ yeast extract, $20 \mathrm{~g} / \mathrm{L}$ glucose and 20 $\mathrm{g} / \mathrm{L}$ mycological peptone (Oxoid, Basingstoke, UK); SD medium: $6.7 \mathrm{~g} / \mathrm{L}$ yeast nitrogen base with ammonium sulphate and without amino acids (Difco) and $20 \mathrm{~g} / \mathrm{L}$ glucose, with $25 \mu \mathrm{g} / \mathrm{mL}$ uridine added as required.

Construction of the grx24 null mutant and reintegrant strain - All primers used in this study are listed in Table II. To make the double mutant strains, the GRX2 and SOD1 genes were disrupted using the ura-blaster method (Fonzi \& Irwin 1993). To achieve this objective, the $G R X 2$ gene was disrupted in the $\Delta$ sod 1 mutant. The Ura- $\Delta$ sodl mutant was kindly provided by Dr Sa-Ouk Kang (Laboratory of Biophysics, Seoul National University, Republic of Korea). The GRX2 disruption cassette pGC4, which was previously generated (Chaves et al. 2007), was released by digestion with HindIII and BanII and GRX2 was disrupted by sequential rounds of transformation into strain $\triangle$ sodl. The URA3 marker was recycled by selection on $\mathrm{SD}$ medium plus 5-fluoroorotic acid $(1 \mathrm{mg} / \mathrm{mL})$ and uridine $(50 \mu \mathrm{g} / \mathrm{mL})$. Gene disruption was confirmed by polymerase chain reaction (PCR). To avoid potential problems associated with ectopic expression of URA3 (Brand et al. 2004), the Ura- $\Delta$ sodl/grx2 mutant was transformed with StuI-digested CIp10 plasmid (Murad et al. 2000), thus ensuring URA3 expression at the neutral RPS1 locus (orf19.3002).

As a control, each of these genes was then individually reintegrated. The $\Delta \operatorname{sod} 1 / g r x 2+G R X 2$ mutant was con- 
TABLE I

Candida albicans mutant strains

\begin{tabular}{|c|c|c|c|}
\hline Strain & $\begin{array}{l}\text { Parent } \\
\text { strain }\end{array}$ & Genotype & Source \\
\hline NGY 152 & CAI4 & As CAI4 but $R P S 1 / r p s 1 \Delta:: \mathrm{CIp} 10$ & $\begin{array}{c}\text { Brand et al. } \\
\text { (2004) }\end{array}$ \\
\hline $\mathrm{CH} 104$ & CH 103 & As CAI4 but $\operatorname{sod} 1 \Delta::$ hisG/sodl $\Delta:$ :hisG & $\begin{array}{l}\text { Hwang et al. } \\
\text { (2002) }\end{array}$ \\
\hline GCY 209 & CH 104 & 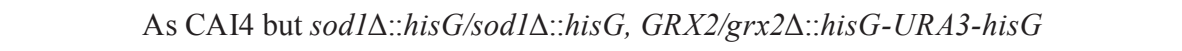 & This paper \\
\hline GCY 210 & GCY 209 & 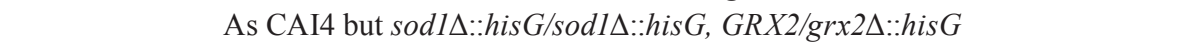 & This paper \\
\hline GCY 211 & GCY 210 & 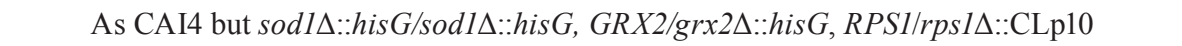 & This paper \\
\hline GCY 212 & GCY 210 & 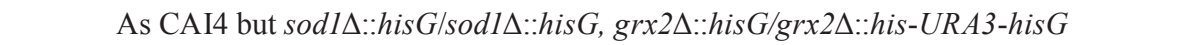 & This paper \\
\hline GCY 213 & GCY 212 & 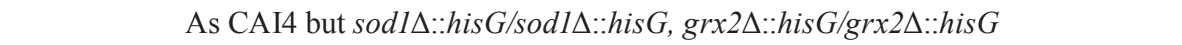 & This paper \\
\hline GCY 214 & GCY 213 & 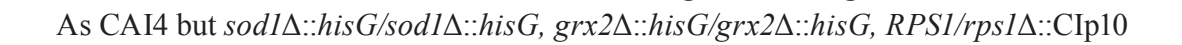 & This paper \\
\hline GCY 215 & GCY 213 & 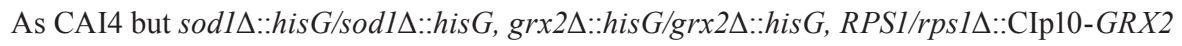 & This paper \\
\hline GCY 216 & GCY 213 & 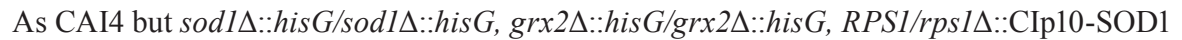 & This paper \\
\hline
\end{tabular}

TABLE II

Primers used in this study

\begin{tabular}{lrc}
\hline Primer & Sequence (5'-3') & Target for amplification \\
\hline GRX2SF & GAGAAAGATCGTGGATTTGG & GRX2 screening forward in the upstream region \\
GRX2SR & CAATACCATTCTGACCAACC & $G R X 2$ screening reverse in the downstream region \\
RP10-GS & TACATTCCTACTCCGTTCG & $R P 1$ sequence in CAI4 genome \\
CIp-10 & GATATCGAATTCACGCGTAG & CIp10 plasmid \\
SOD1SF & AGATCTGCAACAACCAATAGGTAAACGC & $S O D 1$ promoter + Bg II restriction site \\
SOD14 rev & AGATCTGGTTTAGGCTTAAGCTGTAG & $S O D 1$ terminator + Bg II restriction site \\
\hline
\end{tabular}

structed by transforming the $\Delta \operatorname{sod} 1 /$ grx 2 mutant with the reintegrant cassette pGC6, which was previously generated (Chaves et al. 2007). The pGC6 plasmid insert was subcloned into the NotI site of CIp10. The resulting plasmid was digested with StuI and then transformed into the Ura- $\Delta \operatorname{sod} 1 /$ grx 2 null mutant. To generate the $\Delta$ sod $1 /$ grx2+SOD1 mutant, a new reintegrant cassette, pGC8, was created. Therefore, the SOD1 open-reading frame plus 938 bp of its promoter and 404 bp of its terminator was amplified by PCR (primers SOD1SF and SOD14 rev) and the product was cloned into pGEM-T Easy (Promega Ltd, Southampton, UK). The plasmid insert was subcloned into the NotI site of CIp10 and the resulting plasmid was digested with $S t u I$ and transformed into the Ura-4sod1/grx2 null mutant.

C. albicans growth rate determination - Growth rates were measured in duplicate. A volume from an overnight culture in NGY was transferred to YPD broth or RPMI1640 (Gibco, Paisley, UK) to give an initial optical density $(\mathrm{OD})_{600} \mathrm{~nm}=0.05$ and the culture was incubated at $37^{\circ} \mathrm{C}$ with rotation at $200 \mathrm{rpm}$ in a gyratory shaker. Growth was measured using the $\mathrm{OD}_{600} \mathrm{~nm}$ vs. a medium blank. Maximum growth rates were determined from the logarithms of values taken in the exponential phase.
Tests for hyphal formation - For the induction of hyphal formation on solid media, the cells were grown in NGY, centrifuged and washed three times in water. From a suspension adjusted to $10^{9}$ cells $/ \mathrm{mL}, 5 \mu \mathrm{L}$ was spotted on the surface of Spider (Liu et al. 1994) and GlcNAc agars (20 g/L N-acetyl-D-glucosamine, $6.7 \mathrm{~g} / \mathrm{L}$ yeast nitrogen base, $16 \mathrm{~g} / \mathrm{L}$ micro agar) in triplicate. The plates were incubated for seven days at $30^{\circ} \mathrm{C}$.

For tests in liquid media, an adaptation of Odds et al. (2000) was used. Therefore, the cells were grown, washed and standardised to an initial concentration of $10^{6}$ cells $/ \mathrm{mL}$ in $10 \%$ foetal calf serum (FCS), YPD + $10 \%$ FCS and GlcNAc pre-warmed to $37^{\circ} \mathrm{C}$ and incubated at the same temperature with gyratory shaking (9,200 rpm). After 1 and 3-h incubation periods, culture samples were mixed with an equal volume of $10 \%$ formaldehyde to arrest further development. The 1-h sample was examined microscopically to determine the percentage of cells bearing evaginations. The 3-h sample was examined to approximate the mean morphology index (MI) (Merson-Davies \& Odds 1989), in which a value close to 1 indicates a population of spheroidal yeast cells and value close to 4 indicates a population of true hyphal cells. Values between 1-4 indicate mixed or pseudohyphal morphologies (Chaves et al. 2007). 
Sensitivity of C. albicans to oxidative stress inducers - The method of Izawa et al. (1995) was used with some modifications to determine the sensitivity of C. albicans to oxidative stress inducers. Yeast cells grown in NGY were standardised to $2 \times 10^{7}$ cells $/ \mathrm{mL}$. Five-microlitres volumes of a 10-fold dilution series prepared from this suspension were spotted on the surface of YPD agar plates containing concentrations (from 0.5-2.5 mM) of menadione and diamide. The plates were incubated for $48 \mathrm{~h}$ at $30^{\circ} \mathrm{C}$. Alternatively, $50-\mu \mathrm{L}$ volumes of NGYgrown yeast cells were transferred to 5-mL YPD broth with and without the addition of menadione or diamide $(0.5-2.0 \mathrm{mM})$ and incubated in a rotator wheel for $16 \mathrm{~h}$ at $30^{\circ} \mathrm{C}$. The $\mathrm{OD}_{600} \mathrm{~nm}$ was determined for the control and test tubes. Sensitivity to the compounds was measured by examining growth in the presence of compounds as a percentage of control growth.

The susceptibility of C. albicans killing by PMN - PMN freshly isolated from blood samples of healthy volunteers on the day of the experiment (Fradin et al. 2005) was suspended in Eagle's minimal essential medium $+20 \mathrm{mM}$ HEPES ( $\mathrm{pH} 7.2)$ and standardised to $8 \times$ $10^{5} \mathrm{PMN} / \mathrm{mL}$. C. albicans cells grown overnight in NGY were centrifuged, washed three times in saline and resuspended at $5 \times 10^{6}$ yeast cells $/ \mathrm{mL}$ in HEPES-buffered Eagle's minimal essential medium containing one-tenth of a volume of fresh human plasma. Equal volumes of PMN and yeast cell suspensions were mixed and incubated at $37^{\circ} \mathrm{C}$ for $1 \mathrm{~h}$ with rotation at $50 \mathrm{rpm}$. Control suspensions contained C. albicans without PMN. The suspensions were centrifuged and the pellets were resuspended in water to lyse the PMN. After three cycles of washing and resuspension, viable C. albicans cell counts were determined by plating a 10 -fold dilution series on YPD agar. Yeast cell susceptibility was determined as the mean difference between viable counts in the presence and absence of PMN. The assays were performed in triplicate (Chaves et al. 2007).

Virulence of $C$. albicans in the murine $I V$ challenge model - Immunocompetent female BALB/c mice with a weight range from 17-23 g were supplied with food and water ad libitum. The mice were intravenously inoculated with $C$. albicans strains that had been grown overnight in NGY, washed and resuspended in saline. The inoculum was standardised to allow for an injection of 2-3 $\times$

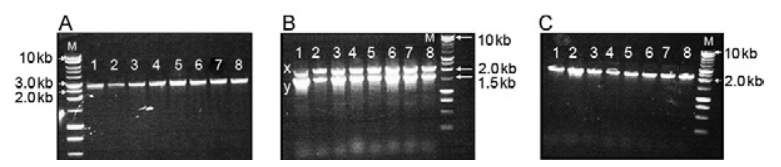

Fig. 1: Candida colony diagnostic polymerase chain reaction. A: generation of $\Delta$ sodl/grx2 null mutant strain (demonstrated with GRX2SF and GRXSR primers). All colonies represent transformants after post5FOA step (expected band size $2.6 \mathrm{~kb}$ ); B: generation of a GRX2 reintegrant in the $\Delta$ sodl/grx 2 background checked with GRX2 SF and GRX2 SR primers [x: RPS1 locus allele (1.9 kb); y: GRX2 disrupted alleles $(1.5 \mathrm{~kb})]$; $\mathrm{C}$ : generation of a SOD1 reintegrant in the $\Delta$ sodl/ grx2 background checked with SOD1 SF and SOD 14 rev primers (expected band size $2.1 \mathrm{~kb}$ ); M: $1 \mathrm{~kb}$ ladder.
$10^{4}$ colony-forming unit/g mouse body weight. The mice were examined daily. Animals that displayed a loss of body weight $>20 \%$ or signs of serious illness were humanely terminated and survival curves were performed.

Statistical analysis - Means \pm standard deviations were determined from the results of at least three independent experiments. Differences between values for phenotypic tests were analysed using Student's $t$ test. Animal survival data were compared with KaplanMeier/LogRank statistics. $p<0.05$ were considered significant for all comparisons.

\section{RESULTS}

Gene disruptions and reintegrations - The $\Delta$ sodll grx2 mutant (GCY 213) was successfully generated by deleting $1,583 \mathrm{bp}$ from the central region of the GRX2 gene in the $\Delta$ sodl mutant (GCY 200) using the "Urablasting" technique (Fonzi \& Irwin 1993) (Fig. 1A). The URA3 gene was reintegrated at the neutral RPS1 locus to avoid ectopic URA3 expression problems (Brand et al. 2004), creating the mutant GCY 214. The GRX2 gene and URA3 were integrated at the RPS1 locus of the $\triangle$ sod1/ grx2 null mutant to generate the $\Delta$ sod1/grx $2+G R X 2$ reintegrant (GCY 215) (Fig. 1B). In the same manner, the SODI gene and URA3 were integrated at the RPSI locus of the $\Delta$ sodl/grx2 null mutant to generate the $\Delta$ sodll grx $2+$ SOD1 reintegrant (GCY 216) (Fig. 1C).

Virulence phenotypic properties of the mutants in vitro - The growth rates of the yeast cell null double mutant GCY 214 and the GRX2 and SOD1 reintegrant strains (GCY 215 and GCY 216, respectively) were similar to that of the wild-type, NGY 152.

Hyphae formation of the mutants on solid and liquid media - The colony morphologies on Spider, YPD $+20 \%$ serum and GlcNAc agars were slightly different for the double mutant compared with NGY 152. Specifically on the Spider medium, the mutants formed a more wrinkled and less filamentous form (Fig. 2). During the first hour of incubation, the double mutant $\Delta$ sodl/grx2 (GCY 214) and double mutant reintegrant strains $\Delta$ sod1/ grx $2+G R X 2$ and $\triangle$ sodl/grx $2+S O D 1$ (GCY 215 and GCY 216 , respectively) demonstrated an even more noticeable delay in their ability to evaginate than the single mutants $\Delta$ sodl 1 and $\Delta g r x 2$ (previously generated) (Chaves et al. 2007). The heterozygote for the double mutant $\Delta$ sodl/ grx2/GRX2 (GCY 211), double mutant GCY 214 and re-

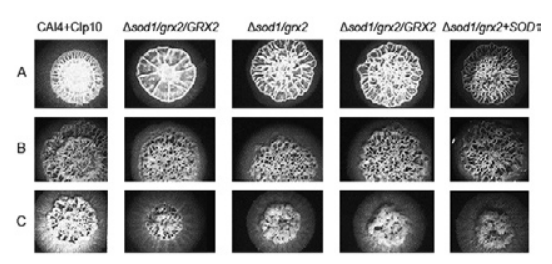

Fig. 2: hyphae formation on solid media. A: Spider medium; B: yeast extract-peptone-dextrose $+10 \%$ serum; C: GlcNac. Plates were incubated in triplicates at $30^{\circ} \mathrm{C}$ for seven days. 
integrant strains GCY 215 and GCY 216 did not evaginate during the first hour of incubation in the YPD + $10 \%$ serum. When grown in $10 \%$ serum in water (the most potent germ tube inducer), all of the strains had fewer than $20 \%$ evaginating cells, a very different result compared with the control strain NGY 152, in which nearly $100 \%$ of the cells evaginated during the first hour of incubation. Evagination in GlcNAc was also less evident in the double mutant strain series than the single mutants and both had fewer cells evaginating than the control strain NGY 152. The disruption of both genes appeared to have a stronger effect on early germ tube formation compared with when only one gene of each was disrupted (Fig. 3).

After $3 \mathrm{~h}$ of incubation, the MI showed noticeable differences for the double mutant strain series. The mean MI was less than 2.0 for all strains in the YPD $+10 \%$ serum and the double mutant GCY 214 had an MI close to 1.0 , indicating a lack of ability to form hyphae under this condition. All of the mean MIs were significantly lower than the control strain NGY $152(\mathrm{p}<0.05)$. In addition, the MI was lower for the double mutant strain series compared with NGY than the single mutants when the cells were induced to form hyphae in the presence of $10 \%$ serum (Chaves et al. 2007). The double mutant strain series formed fewer true hyphae, with a mean $\mathrm{MI}$ in the range of 3.5-3.7. Although this difference was not large, it was still statistically significant $(p<0.05)$. When cells were grown in GlcNac, the mean MI was approximately 2.0 or below for all of the double mutant strain series (Fig. 4).

Sensitivity to oxidative stress inducers - The heterozygous GCY 211, double mutant GCY 214 and GRX2 reintegrant GCY 215 were sensitive to menadione. The reintroduction of the SODI gene restored resistance to this chemical compound in the SOD1 reintegrant strain, GCY 216 (Fig. 5). Disruption of one copy of the GRX2 gene in the single $\Delta$ sodl mutant (GCY200) did not lead to any difference because the heterozygous strain $\Delta$ sod $1 /$ grx2/GRX2 (GCY 211) was still sensitive to $2.5 \mathrm{mM}$ di-

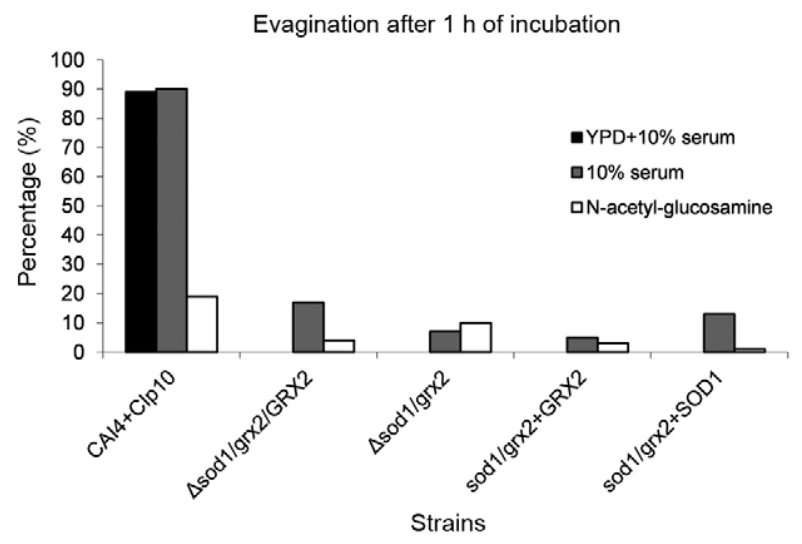

Fig. 3: percentage of evagination in the oxidative stress double mutant strain series cells after $1 \mathrm{~h}$ of incubation in liquid media at $37^{\circ} \mathrm{C}, 200$ rpm. YPD: yeast extract-peptone-dextrose. amide. Following the same trend, as previously observed (Chaves et al. 2007), the knockout of both copies of the GRX2 gene (generating GCY 214) led to a phenotype resistant to diamide. The reintroduction of one copy of GRX2 (generating GCY 215; $\Delta$ sod1/grx $2+G R X 2$ ) led this double mutant reintegrant to become sensitive again, similar to the heterozygous $\Delta \operatorname{sod} 1 / \operatorname{gr} x 2 / G R X 2$ (GCY 211). In the same manner, the introduction of the SOD1 gene, creating $\triangle$ sod1/grx2+SOD1 (GCY 2160), maintained the same diamide-resistant phenotype when both copies of the GRX2 genes were disrupted (Fig. 6). We reproduced the same results obtained for the tests in liquid media by using agar plates with different concentrations of menadione and diamide (Fig. 7).

PMN killing assays of the mutants - Interactions with human peripheral PMNs revealed that the double mutant strain series was more susceptible to killing than the control strain NGY 152. After an incubation period of $1 \mathrm{~h}$ at $37^{\circ} \mathrm{C}$ in the presence (test) or absence of PMNs (control) and incubating the C. albicans cells at $30^{\circ} \mathrm{C}$ on YPD agar plates, the heterozygous double mutant strain $\Delta$ sod1/grx2/GRX2 (GCY 211), double mutant null $\Delta$ sod1/ grx2 (GCY 214) and $\triangle$ sodl/grx2+SOD1 (GCY 216) reintegrant strains were more susceptible to PMN killing

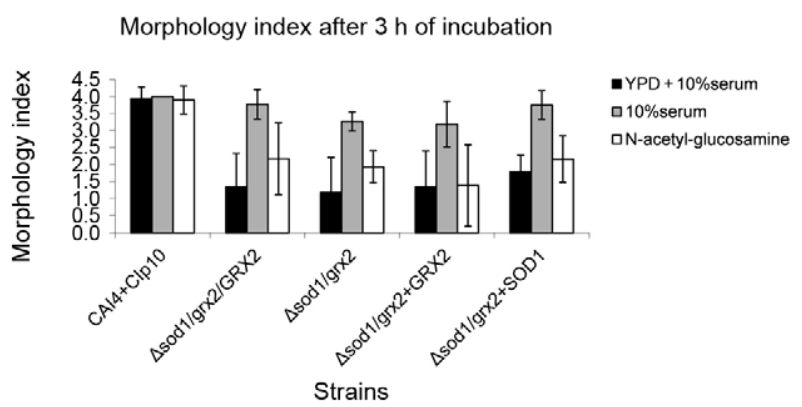

Fig. 4: morphology index (MI) the oxidative stress double mutant strain series cells after $3 \mathrm{~h}$ of incubation in liquid media at $37^{\circ} \mathrm{C}, 200$ $\mathrm{rpm}$. Bars represent variation on MI of cells. For all the mutants in all conditions tested, $\mathrm{p}<0.05$ relative to CAI4+CIp10. YPD: yeast extract-peptone-dextrose.

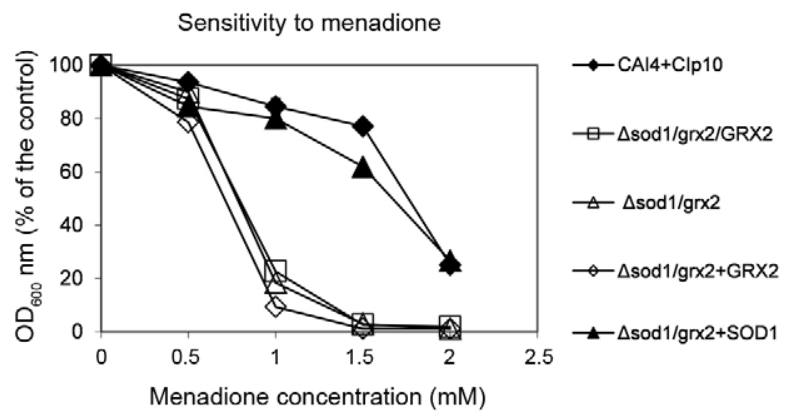

Fig. 5: sensitivity to menadione in liquid medium $(0.5-2.0 \mathrm{mM})$. The tubes were incubated at $30^{\circ} \mathrm{C}$ in a rotator wheel for $16 \mathrm{~h}$. Growth optical density (OD) $600 \mathrm{~nm}$ was expressed as a percentage of control growth. Bars represent standard deviations for three independent experiments. 
( $\mathrm{p}<0.05$ ). However, only the $\Delta$ sodl/grx $2+G R X 2$ (GCY 215) mutant cells were less efficiently killed by the PMNs after $1 \mathrm{~h}$ (Fig. 8). This number is closer to the findings for the single mutant killings (Chaves et al. 2007).

Virulence of the mutants in an animal model of systemic infection - The virulence of the double mutant strain series did demonstrate some degree of attenuation by disruption of the two genes related to oxidative stress in C. albicans. Survival curves demonstrated that the double null mutant $\Delta$ sodl/grx2 (GCY 214) and reintegrant strain $\triangle$ sodl/grx $2+S O D 1$ (GCY 216) were the most attenuated in virulence ( $40 \%$ and $50 \%$ survivors at the end of the experiment, respectively; $p<0.05$ ). The reintegrant strain $\Delta$ sodl/grx2 $+G R X 2$ (GCY 215) had a survival curve comparable to the control strain NGY152, demonstrating some degree of regaining virulence when the GRX2 gene was reintegrated (Fig. 9).

\section{DISCUSSION}

In the present study, we evaluated the role of two different genes related to oxidative stress in C. albicans. The first, the GRX2 gene, encodes a Grx and the other, the $S O D$ gene, encodes a copper and zinc-containing SOD. We hypothesised that the disruption of two genes involved in oxidative stress would lead to a strain with an increased attenuation in virulence and higher degree of susceptibility to chemical compounds that induce oxidative stress.

The ability to combat ROS is vital for microbial pathogenesis to either cope with ROS generated as a consequence of their own metabolism or escape from

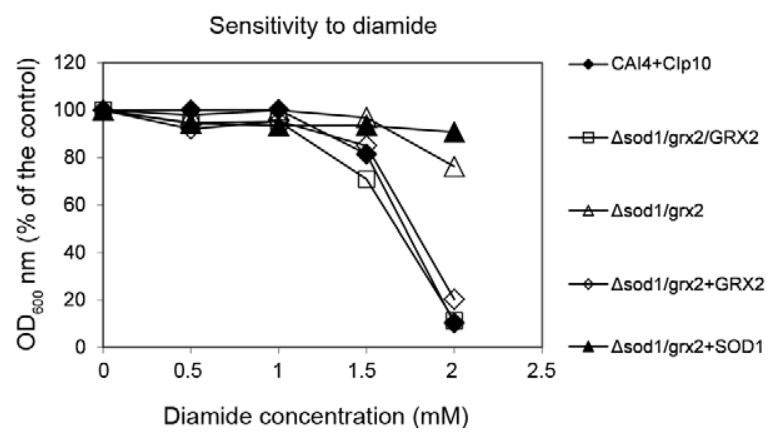

Fig. 6: sensitivity to diamide in liquid medium $(0.5-2.0 \mathrm{mM})$. The tubes were incubated at $30^{\circ} \mathrm{C}$ in a rotator wheel for $16 \mathrm{~h}$. Growth optical density (OD) $600 \mathrm{~nm}$ was expressed as a percentage of control growth. Bars represent standard deviations for three independent experiments.

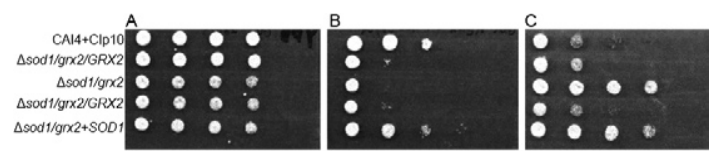

Fig. 7: sensitivity to diamide in liquid medium $(0.5-2.0 \mathrm{mM})$. The tubes were incubated at $30^{\circ} \mathrm{C}$ in a rotator wheel for $16 \mathrm{~h}$. Growth optical density (OD) $600 \mathrm{~nm}$ was expressed as a percentage of control growth. Bars represent standard deviations for three independent experiments. human phagocytic cells (Cabiscol et al. 2000, Lamarre et al. 2001, Hwang et al. 2002, 2003, Martchenko et al. 2004, Gonzalez-Parraga et al. 2005). Some chemical compounds have been used to induce oxidative stress in microorganisms, such as menadione and diamide.

Oxidative stress may be generated by the addition of menadione (2-methylnaphthalene-1,4-dione), a polycyclic aromatic ketone commonly used in yeast studies (Grant 2001, Osorio et al. 2003), which accepts an electron from a respiratory carrier and transfers it to molecular oxygen (a redox cycling agent), stimulating superoxide formation without inhibiting the respiratory chain (Halliwell \& Gutteridge 2007). Diamide is a thiol-specific oxidant that can readily oxidise GSH, leading to molecular crosslinking (Hwang et al. 2003, Herrero et al. 2008).

As previously observed by Hwang et al. (2002) and then by Chaves et al. (2007), the $\Delta$ sodl mutant is sensitive to menadione. The $\Delta g r x 2$ mutant is less sensitive to this chemical compound than the mutant $\Delta$ sodl and very resistant to diamide (Chaves et al. 2007). The idea of specific roles for oxidative stress genes in C. albicans was further reinforced when the double mutant strain

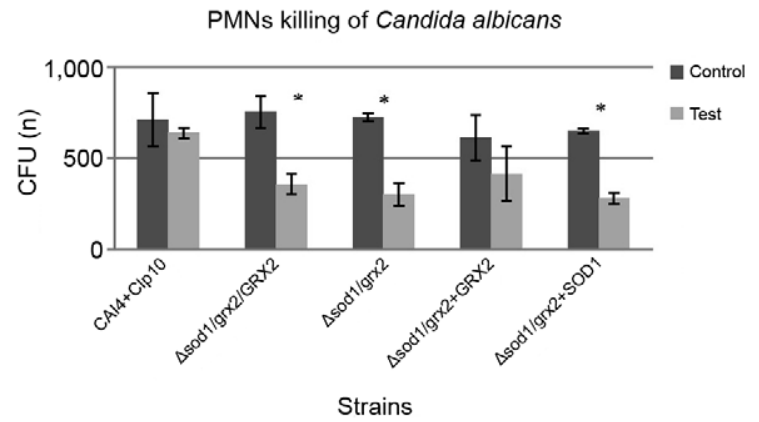

Fig. 8: oxidative stress double mutant strain series killing by polymorphonuclear neutrophils (PMNs). Cells were incubated in triplicate for $1 \mathrm{~h}$ in the presence of PMNs and colony-forming unit (CFU) were determined after three days of incubation of viable cells. Reduction in mean CFU of yeasts exposed to PMNs was expressed as a percentage of mean CFU for control suspensions.

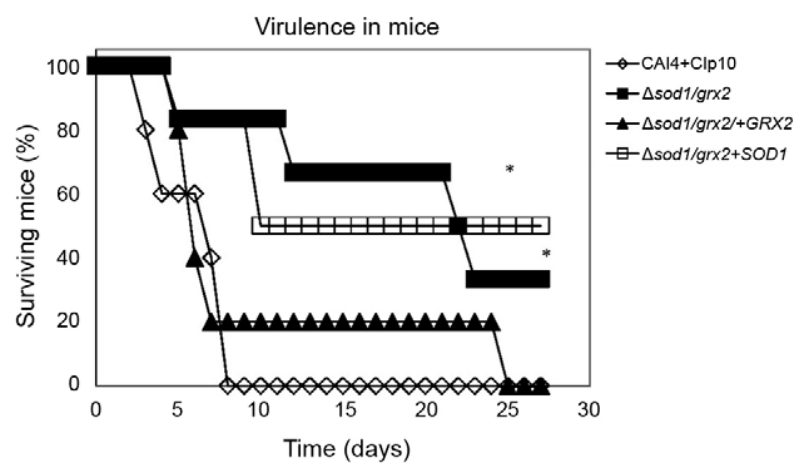

Fig. 9: survival of groups of six mice challenged IV with 5.7 x 104 colony-forming unit/g of Candida albicans null mutant strains. All the strains except $\Delta$ sodl/grx $2+G R X 2$ were attenuated in virulence when compared to the control strain CAI4+CIp10. Asterisks mean $\mathrm{p}<0.05$. 
series was tested for susceptibility to oxidative stress generators in the present study. When one copy of GRX2 was disrupted in the $\Delta s o d l$ background, generating the heterozygous strain $\Delta$ sod1/grx2/GRX2 (GCY 211), this strain remained sensitive to menadione. When both copies of GRX2 were disrupted, generating the double mutant $\Delta$ sodl/grx2 (GCY 214), the phenotype remained the same. Furthermore, the reintegration of one copy of GRX2, generating the $\Delta$ sodl/grx $2+G R X 2$ (GCY 215) mutant, had no effect, confirming that the response of $G R X 2$ is minimal when the stress generated is due to the generation of intracellular $\mathrm{O}_{2}^{-}$(menadione). This hypothesis was conclusive because the reintegration of only one copy of SOD1 (generating the $\triangle$ sodl/grx2+SOD1 mutant) conferred resistance to menadione.

Another completely different response was observed in the double mutant strain series when they were grown with diamide. The deletion of one copy of GRX2 in the $\Delta$ sodl background (generating the $\Delta$ sodl/grx $2 /$ GRX2 mutant) was insufficient to lead to resistance to diamide. The deletion of two copies of the gene, generating the double mutant $\Delta$ sodl/grx2 (GCY 214), led to resistance, as was observed for the $\Delta g r x 2$ mutant (Chaves et al. 2007). This result confirms that $S O D 1$ plays no role in combating the oxidative stress generated by diamide because the reintroduction of GRX2 (generating the $\Delta$ sod1/gr $x 2+G R X 2$ mutant) again rendered this mutant strain sensitive to diamide. The $\Delta$ sod1/grx $2+S O D 1$ mutant was resistant to diamide, indicating that the reintroduction of SOD1 did not have an effect, confirming again that GRX2 and not SOD1 is involved in the resistance to the oxidative stress generated by diamide. Distinct roles for menadione and diamide in generating oxidative stress have also been observed with Aspergillus nidulans (Pocsi et al. 2005).

Herrero et al. (2008) demonstrated that Sods are particularly related to ROS detoxification and Grx in the control of the redox state of protein sulfhydryl groups in Saccharomyces cerevisiae. Furthermore, the Candida genome database (candidagenome.org/) currently describes four Grx (GRX1, GRX2, GRX3 and GRX5) and two thioredoxins (TRX1 and TRX2) for this species, further reinforcing that resistance to diamide is related to a compensatory mechanism for other Grx (or even thioredoxins) in C. albicans because these other genes might be up-regulated to act as thiol oxidoreductases responsible for reducing the protein disulphides or GSH-protein mixed disulphides generated during diamide-induced oxidative stress. Conversely, Luikenhuis et al. (1998) found different functions for defences against diamide in $S$. cerevisiae that were dependent on the growth phase. In exponential phase cells, the lack of both Grx resulted in a resistance to diamide, whereas in stationary phase cells, the deletion of GRXI alone led to resistance, suggesting that a complexity of mechanisms for different Grx in C. albicans may exist.

Regarding hyphae formation, the double mutant $\Delta$ sodl/grx2 had a markedly lower mean MI when grown in YPD $+10 \%$ serum, $10 \%$ serum and GlcNac. GonzalesParraga et al. (2005) investigated a possible relationship between levels of GSH and oxidised GSH (GSSH) and germ tube formation induced by serum in C. albicans, specifically during the first hour of incubation. The levels of GSH decreased, while the levels of GSSH remained unmodified. Grx are responsible for reducing GSSH to GSH. Therefore, the lack of Grx (due to GRX2 disruption) and GSSH accumulation may partially explain the inability to form hyphae in the double mutant, i.e., due to ROS accumulation. SOD5 has been demonstrated to relate to hyphae formation by transcript profiling; i.e., this gene is up-regulated during the process of hyphae formation (Nantel et al. 2002) Furthermore, Martchenko et al. (2004) demonstrated with Northern analysis that SOD5 expression during hyphae formation is due to the presence of serum. SODI is also transcribed in the presence of serum (Lamarre et al. 2001), which could explain why a double mutant for two oxidative stress genes (GRX2 and $S O D 1$ ) is defective in hyphae formation.

We also observed that our double mutant $\Delta$ sod $1 /$ grx 2 is very susceptible to PMN killing. Conversely, both genes were up-regulated in the presence of PMNs (Fradin et al. 2005). However, in addition to SOD1 and GRX2 appearing to play different and specific roles in response to the oxidative stress generated by the chemical inducers menadione and diamide, GRX2 also appears to play a major role in surviving PMN killing.

The double mutant strain series was unexpectedly not more attenuated in mouse virulence than the single mutants generated by Chaves et al. (2007). However, the double null mutant $\triangle$ sod1/grx 2 and the $\triangle$ sodl/gr $x 2+S O D 1$ reintegrant were still attenuated in virulence, confirming the importance of oxidative stress genes for virulence in mice. Surprisingly, $\Delta$ sodl/grx $2+G R X 2$, which was also more resistant to PMN killing, regained some degree of virulence in mice, reinforcing the role of this gene in $C$. albicans pathogenesis.

The double mutant generated here, $\Delta \operatorname{sod} 1 / \operatorname{gr} x 2$, had a defect in hyphae formation and was susceptible to PMN killing, corroborating the hypothesis that both genes are important for C. albicans virulence. Further studies are required to elucidate the specific role of the importance of this complex antioxidant system and its relation to $C$. albicans virulence.

\section{REFERENCES}

Battistoni AG, Donnarumma, Greco R, Valenti P, Rotilio G 1998. Overexpression of a hydrogen peroxide-resistant periplasmic $\mathrm{Cu}$, $\mathrm{Zn}$ superoxide dismutase protects Escherichia coli from macrophage killing. Biochem Biophys Res Commun 243: 804-807.

Bink A, Vandenbosch D, Coenye T, Nelis H, Cammue BP, Thevissen K 2011. Superoxide dismutases are involved in Candida albicans biofilm persistence against miconazole. Antimicrob Agents Chemother 55: 4033-4037.

Brand A, MacCallum DM, Brown AJ, Gow NA, Odds FC 2004. Ectopic expression of URA3 can influence the virulence phenotypes and proteome of Candida albicans but can be overcome by targeted reintegration of URA3 at the RPS10 locus. Eukaryot Cell 3: 900-909.

Cabiscol, Tamarit EJ, Ros J 2000. Oxidative stress in bacteria and protein damage by reactive oxygen species. Int Microbiol 3: 3-8.

Chaves GM, Bates S, Maccallum DM, Odds FC 2007. Candida albicans $G R X 2$, encoding a putative glutaredoxin, is required for virulence in a murine model. Genet Mol Res 6: 1051-1063. 
Chaves GM, Santos FP, Colombo AL 2012. The persistence of multifocal colonisation by a single $\mathrm{ABC}$ genotype of Candida albicans may predict the transition from commensalism to infection. Mem Inst Oswaldo Cruz 107: 198-204.

Colombo AL, Guimaraes T, Silva LR, de Almeida Monfardini LP, Cunha Ak, Rady P, Alves T, Rosas RC 2007. Prospective observational study of candidemia in São Paulo, Brazil: incidence rate, epidemiology, and predictors of mortality. Infect Control Hosp Epidemiol 28: 570-576.

Fonzi WA, Irwin MY 1993. Isogenic strain construction and gene mapping in Candida albicans. Genetics 134: 717-728.

Fradin CP, De Groot P, Maccallum D, Schaller M, Klis F, Odds FC, Hube B 2005. Granulocytes govern the transcriptional response, morphology and proliferation of Candida albicans in human blood. Mol Microbiol 56: 397-415.

Frohner IE, Bourgeois C, Yaysyk K, Majer O, Kuchler K 2009. Candida albicans cell surface superoxide dismutases degrade hostderived reactive oxygen species to escape innate immune surveillance. Mol Microbiol 71: 240-252.

Gonzalez-Parraga P, Marin FR, Aguelles JC, Hernandez JA 2005. Correlation between the intracellular content of glutathione and the formation of germ-tubes induced by human serum in Candida albicans. Biochim Biophys Acta 1722: 324-330.

Gow NA, Netea MG, Munro CA, Ferwerda G, Bates S, Mora-Montes HM, Walker L, Jansen T, Jacobs L, Tsoni V, Brown GD, Odds FC, Van der Meer JW, Brown AJ, Kullberg BJ 2007. Immune recognition of Candida albicans beta-glucan by dectin-1. J Infect Dis 196: 1565-1571.

Grant CM 2001. Role of the glutathione/glutaredoxin and thioredoxin systems in yeast growth and response to stress conditions. Mol Microbiol 39: 533-541.

Halliwell B, Gutteridge JMC 2007. Free radicals in biology and medicine, 4th ed., University Press, Oxford, $851 \mathrm{pp}$.

Herrero E, Ros J, Belli G, Cabiscol E 2008. Redox control and oxidative stress in yeast cells. Biochim Biophys Acta 1780: 1217-1235.

Hwang CS, Baek YU, Yim HS, Kang SO 2003. Protective roles of mitochondrial manganese-containing superoxide dismutase against various stresses in Candida albicans. Yeast 20: 929-941.

Hwang CS, Rhie GE, Oh JH, Huh WK, Yim HS, Kang SO 2002. Copper-and zinc-containing superoxide dismutase (Cu/ZnSOD) is required for the protection of Candida albicans against oxidative stresses and the expression of its full virulence. Microbiology 148: 3705-3713.

Izawa S, Inoue Y, Kimura A 1995. Oxidative stress response in yeast: effect of glutathione on adaptation to hydrogen peroxide stress in Saccharomyces cerevisiae. FEBS Lett 368: 73-76.

Karkowska-Kuleta J, Rapala-Kozik M, Kozok A 2009. Fungi pathogenic to humans: molecular bases of virulence of Candida albicans, Cryptococcus neoformans and Aspergillus fumigatus. Acta Biochim Pol 56: 211-224.

Lamarre C, LeMay JD, Deslauries N, Bourbonnai Y 2001. Candida albicans expresses an unusual cytoplasmic manganese-containing superoxide dismutase (SOD3 gene product) upon the entry and during the stationary phase. J Biol Chem 276: 43784-43791.

Liu H, Kohler J, Fink GR 1994. Suppression of hyphal formation in Candida albicans by mutation of a STE12 homolog. Science 266: 1723-1726.

Luikenhuis S, Perrone G, Dawes IW, Grant CM 1998. The yeast Saccharomyces cerevisiae contains two glutaredoxin genes that are required for protection against reactive oxygen species. Mol Biol Cell 9: 1081-1091.

Martchenko M, Alarco AM, Harcus D, Whiteway M 2004. Superoxide dismutases in Candida albicans: transcriptional regulation and functional characterization of the hyphal-induced SOD5 gene. Mol Biol Cell 15: 456-467.

Merson-Davies LA, Odds FC 1989. A morphology index for characterization of cell shape in Candida albicans. J Gen Microbiol 135: 3143-3152.

Murad AM, Lee PR, Broadbent ID, Barelle CJ, Brown AJ 2000. CIp10, an efficient and convenient integrating vector for Candida albicans. Yeast 16: 325-327.

Nantel A, Dignard D, Bachewich C, Harcus D, Marcil A, Bouin AP, Sensen CW, Hogues H, van het Hoog M, Gordon P, Rigby T, Benoit F, Tessier DC, Thomas DY, Whiteway M 2002. Transcription profiling of Candida albicans cells undergoing the yeast-tohyphal transition. Mol Biol Cell 13: 3452-3465.

Nasution O, Srinivasa K, Kim M, Kim YJ, Kim W, Jeong W, Choi W 2008. Hydrogen peroxide induces hyphal differentiation in Candida albicans. Eukaryot Cell 7: 2008-2011.

Nicola AM, Casadevall A, Goldman DL 2008. Fungal killing by mammalian phagocytic cells. Curr Opin Microbiol 11: 313-317.

Odds FC, Van Nuffel L, Gow NA 2000. Survival in experimental Candida albicans infections depends on inoculum growth conditions as well as animal host. Microbiology 146: 1881-1889.

Osorio H, Carvalho E, del Valle M, Gunther Sillero MA, MoradasFerreira P, Sillero A 2003. H2O2, but not menadione, provokes a decrease in the ATP and an increase in the inosine levels in Saccharomyces cerevisiae. An experimental and theoretical approach. Eur J Biochem 270: 1578-1589.

Pocsi I, Miskei M, Karanyi Z, Emri T, Ayoubi P, Pusztahelyi T, Balla G, Prade RA 2005. Comparison of gene expression signatures of diamide, $\mathrm{H} 2 \mathrm{O} 2$ and menadione exposed Aspergillus nidulans cultures-linking genome-wide transcriptional changes to cellular physiology. BMC Genomics 6: 182.

Schroter C, Hipler UC, Wilmer A, Kunkel W, Wollina U 2000. Generation of reactive oxygen species by Candida albicans in relation to morphogenesis. Arch Dermatol Res 292: 260-264.

Southern P, Horbul J, Maher D, Davis DA 2008. C. albicans colonization of human mucosal surfaces. PLOS ONE 3: e2067.

Srinivasa K, Kim J, Yee S, Kim W, Choi W 2012. A MAP kinase pathway is implicated in the pseudohyphal induction by hydrogen peroxide in Candica albicans. Mol Cells 33: 183-193.

Taylor PR, Tsoni SV, Willment JA, Dennehy KM, Rosas M, Findon H, Haynes K, Steele C, Botto M, Gordon S, Brown GD 2007. Dectin-1 is required for beta-glucan recognition and control of fungal infection. Nat Immunol 8: 31-38.

Tosello ME, Biasoli MS, Luque AG, Magaro HM, Krapp AR 2007. Oxidative stress response involving induction of protective enzymes in Candida dubliniensis. Med Mycol 45: 535-540.

Wysong DR, Christin L, Sugar AM, Robbins PW, Diamond RD 1998. Cloning and sequencing of a Candida albicans catalase gene and effects of disruption of this gene. Infect Immun 66: 1953-1961.

Younes S, Bahnan W, Dimassi HI, Khalaf RA 2011. The Candida albicans Hwp2 is necessary for proper adhesion, biofilm formation and oxidative stress tolerance. Microbiol Res 166: 430-436. 